Article

\title{
Lactational Responses of Heat-Stressed Dairy Goats to Dietary L-Carnitine Supplementation
}

\author{
Nabil Mehaba®, Ahmed A. K. Salama *®) Xavier Such $₫$, Elena Albanell@ and Gerardo Caja \\ Ruminant Research Group (G2R), Animal and Food Science Department, Universitat Autònoma de Barcelona, \\ Bellaterra, 08193 Barcelona, Spain \\ * Correspondence: ahmed.salama@uab.es
}

Received: 16 July 2019; Accepted: 14 August 2019; Published: 16 August 2019

check for updates

Simple Summary: Endogenous carnitine synthesis is reduced by heat stress, and we hypothesized that carnitine supplementation would improve lipid metabolism and performance of dairy goats when exposed to high ambient temperature. In the current study, goats were exposed to thermal-neutral $\left(15\right.$ to $\left.20^{\circ} \mathrm{C}\right)$ or heat stress $\left(28\right.$ to $\left.35^{\circ} \mathrm{C}\right)$ conditions. In each environmental condition, goats were supplemented or not with rumen-protected carnitine in their diets. Goats exposed to heat stress experienced high body temperatures and respiratory rates, and reduced feed intake and milk production. Carnitine supplementation was transferred efficiently to blood, but had no effect on physiological or productive parameters in goats. We conclude that extra carnitine has no beneficial effects on goats' performance and is not needed in thermal-neutral or heat stress conditions.

\begin{abstract}
Heat stress causes significant losses in milk production, and nutritional strategies are needed to alleviate its effects. Endogenous carnitine synthesis is also reduced by heat stress (HS). Carnitine plays a central role in fatty acid oxidation and buffers the toxic effects of acyl groups. We hypothesized that carnitine supplementation would make up for any carnitine deficiencies during HS and improve lipid metabolism. The objective was to evaluate rumen-protected L-carnitine (CAR) supplementation in dairy goats under thermo-neutral (TN) or HS conditions. Four Murciano-Granadina dairy goats were used in a four $\times$ four Latin square design. Goats were allocated to one of four treatments in a two $\times$ two factorial arrangement. Factors were 1$)$ diet: control $(\mathrm{CON})$ or supplementation with CAR $(1 \mathrm{~g} / \mathrm{d})$; and 2) ambient conditions: TN $\left(15\right.$ to $\left.20^{\circ} \mathrm{C}\right)$ or $\mathrm{HS}\left(0900\right.$ to $2100 \mathrm{~h}$ at $35^{\circ} \mathrm{C}, 2100$ to $0900 \mathrm{~h}$ at $28^{\circ} \mathrm{C}$ ). Blood free-, acetyl-, and total-carnitine concentrations increased almost three times by supplementation. Despite this efficient absorption, CAR had no effect on feed intake, milk production or blood metabolites in TN or HS conditions. Heat stress increased rectal temperature and respiratory rate. Additionally, HS goats experienced $26 \%$ loss in feed intake, but they tended to eat longer particle sizes. Compared to TN, heat-stressed goats lost more subcutaneous fat (difference in fat thickness measured before and after each period $=-0.72 \mathrm{vs}$. $+0.64 \mathrm{~mm}$ ). In conclusion, supplemented L-carnitine was efficiently absorbed, but it had no lactational effects on performance of goats under thermo-neutral or heat stress conditions.
\end{abstract}

Keywords: L-carnitine; heat stress; feed sorting; metabolism; dairy goats

\section{Introduction}

Heat stress (HS) causes significant losses in milk yield and milk components in dairy animals [1,2]. Goats are considered more tolerant to HS compared to dairy cows because of their greater sweating rate and lower body weight (BW): surface ratio, allowing greater heat dissipation [3]. However, lactating dairy goats exhibit several changes in performance due to HS, including reductions in feed intake, milk yield, milk fat, and milk protein [3,4]. 
The HS compromises animal performance by directly altering metabolism and the hierarchy of nutrient utilization [5]. For instance, heat-stressed (HSed) goats challenged with epinephrine have lower blood concentrations of non-esterified fatty acids (NEFA) compared to goats under thermal-neutral (TN) conditions, indicating that lipid tissue of HSed goats becomes less sensitive to lipolytic signals [3]. Additionally, blood NEFA and B-hydroxybutyrate (BHB) do not vary between HS and TN goats [3] or cows [1], although they experience negative energy balance. These findings might indicate that HSed animals are not able to use body fat reserves to cover their energy needs. Recently, blood transcriptomics of HSed goats showed the downregulation of several anti-inflammatory pathways, indicating that HSed goats could be in an inflammation status [6]. Inflammation impairs peroxisome proliferator-activated receptor-regulated fatty acid oxidation and carnitine synthesis from lysine [7]. Thus, HSed animals may need more carnitine compared to TN animals.

L-carnitine (CAR) has two main roles in eukaryote cells: 1) A "shuttle role", in the transfer of long-chain fatty acids from cytosol to mitochondria for subsequent $\beta$-oxidation and the production of acetyl-CoA used for energy production (by ketogenesis or in TCA cycle); and 2) the "buffer role" of the acyl groups (by modulation of the acyl-CoA/CoA and reduction of the acyl toxicity by excreting them as carnitine esters) [8].

Heat stress blocks fat mobilization in dairy cows [1,2] and apparently it does the same in dairy goats [3]. However, Hamzaoui et al. [4] exposed goats to HS for four weeks, and reported that blood NEFA levels are greater in HS in the first week than TN, but for the remaining weeks no differences in NEFA are detected. This finding might indicate that HSed goats start to mobilize lipid, but as they are not able to use these fatty acids (presumably because synthesis of carnitine is reduced as indicated above) they stop mobilizing lipid tissue despite the decreased energy intake. Randle [9] reported that the provision of free fatty acids promotes fatty acid oxidation and storage, inhibits glucose oxidation and may promote glucose storage if glycogen reserves are incomplete. Therefore, we hypothesized that CAR supplementation would help in the utilization of fatty acids and improve energy metabolism. The objective of the current study was to determine the influence of L-carnitine supplementation on the physiological and lactational responses in dairy goats under heat stress conditions. To date and to the best of our knowledge, no information is available on the effects L-carnitine supplementation in heat-stressed dairy goats.

\section{Materials and Methods}

Animal care conditions and management practices agreed with the procedures stated by the Ethical Committee of Animal and Human Experimentation of the Universitat Autònoma de Barcelona (CEEAH reference 11/1430) and the codes of recommendations for the welfare of livestock of the Ministry of Agriculture, Food and Environment of Spain.

\subsection{Animals, Treatments, and Management Conditions}

Four multiparous Murciano-Granadina dairy goats (134 \pm 2 days in milk; $2.48 \pm 0.02 \mathrm{~L} / \mathrm{d}$ milk yield; $46.1 \pm 0.5 \mathrm{~kg} \mathrm{BW}$ ) with healthy and symmetrical udders from the herd of the experimental farm of the Universitat Autònoma de Barcelona were used. The design was $4 \times 4$ Latin square with $16-\mathrm{d}$ periods. The first $11 \mathrm{~d}$ were for adaptation, while the last $5 \mathrm{~d}$ were the measurement period. Dietary L-carnitine supplementation increases carnitine levels in blood, milk, liver, and muscles within $1 \mathrm{wk}$ in dairy cows [10]. Consequently, we considered the 16-d experimental periods enough time to study the possible CAR effects.

Goats were allocated to one of 4 treatments in $2 \times 2$ factorial arrangements. Factors were: 1 ) Diet: control without supplementation (CON), or supplementation with $5 \mathrm{~g}$ of rumen-protected CAR (20\% pure L-carnitine; CarnEon20 Rumin-Pro, Kaesler Animal Nutrition, Cuxhaven, Germany); and 2) ambient conditions: $\mathrm{TN}$ ( 15 to $20{ }^{\circ} \mathrm{C}$ and $40 \%$ to $70 \%$ relative humidity throughout the day) or HS (from 0900 to $2100 \mathrm{~h}$ at $35{ }^{\circ} \mathrm{C}$ and from 2100 to $0900 \mathrm{~h}$ at $28{ }^{\circ} \mathrm{C}$ with $45 \% \pm 5 \%$ relative humidity). This resulted in 4 treatment combinations: TN-CON, TN-CAR, HS-CON, and HS-CAR. 
The temperature humidity index $(\mathrm{THI})$ values were calculated according to NRC [11]: THI $=(1.8$ $\left.\times \mathrm{T}_{\mathrm{db}}+32\right)-\left[(0.55-0.0055 \times \mathrm{RH}) \times\left(1.8 \times \mathrm{T}_{\mathrm{db}}-26.8\right)\right]$, where $\mathrm{T}_{\mathrm{db}}$ is the dry bulb temperature $\left({ }^{\circ} \mathrm{C}\right)$ and $\mathrm{RH}$ is the relative humidity (\%). The THI values for TN varied between 59 and 65 throughout the day, whereas for HS, the THI values were 84 and 75 for the day and night, respectively. These THI values used in the current experiment for HSed goats are classfied as "alert" $(80 \leq \mathrm{THI}<85)$ and "normal" (THI < 80) stress levels during the day and night, respectively [12]. The photoperiod was maintained constant 12-12 h (day, 0900 to 2100; night, 2100 to 0900) in both TN and HS conditions. Data of environmental temperature and humidity were recorded every $10 \mathrm{~min}$ by using 2 data loggers (Opus 10, Lufft, Fellbach, Germany).

Throughout the experiment, (mid-March to mid-June), the TN goats were kept indoors, and the temperature was maintained at 15 to $20^{\circ} \mathrm{C}$ with the help of an electric heater equipped with a thermostat (3.5 kW; General Electric, Barcelona, Spain) when necessary. Temperature and relative humidity averaged $17.4 \pm 0.5{ }^{\circ} \mathrm{C}$ and $62 \% \pm 5 \%(\mathrm{THI}=63)$ for the TN goats. The HS goats were kept in a $4 \times 6 \times 2.3 \mathrm{~m}$ climatic chamber (Euroshield, ETS Lindgren-Euroshield Oy, Eura, Finland) provided with a temperature and humidity controlling system (CAREL Controls Ibérica, S.L., Barcelona, Spain). A continuous $90 \mathrm{~m}^{3} / \mathrm{h}$ air turnover was maintained throughout the experiment.

Goats had a 4-wk pre-experimental period under TN conditions for the adaptation to the diet and to the experimental conditions before applying the ambient conditions. When goats were switched from TN to HS conditions, the temperature increased in 2 steps $\left(1 \mathrm{~d}\right.$ at $25^{\circ} \mathrm{C}$ and $1 \mathrm{~d}$ at $30{ }^{\circ} \mathrm{C}$, $45 \pm 5 \%$ humidity), but no transition was applied for the change from HS to TN.

Goats were milked twice daily $(0800$ and $1700 \mathrm{~h})$ using a portable milking machine set at $42 \mathrm{kPa}, 90$ pulses/min, and $66 \%$ pulsation ratio, provided with recording jars ( $5 \mathrm{~L} \pm 5 \%$ ). Milking routine included cluster attachment without udder preparation or teat cleaning, machine milking, machine stripping before cluster removal, and teat dipping in an iodine solution (P3-ioshield, Ecolab Hispano-Portuguesa, Barcelona, Spain).

The $5 \mathrm{~g}$ of CAR supplement were daily weighed by an electronic scale (Mobba Barcelona, Barcelona, Spain), mixed with $50 \mathrm{~g}$ crushed barley, and offered individually before the morning milking. The CON goats were also fed $50 \mathrm{~g}$ crushed barley without CAR supplementation. The CAR product contained $11.6 \%$ crude proein and $50.8 \%$ ether extract on dry matter (DM) basis. The $5 \mathrm{~g}$ daily dose of the commercial CAR supplement provided $1 \mathrm{~g}$ pure L-carnitine. The CAR dose $(1 \mathrm{~g})$ in the current study is equivalent to $0.056 \mathrm{~g} / \mathrm{kg} \mathrm{BW}^{0.75}$, which is similar to the dosage used by LaCount et al. [13] in dairy cows $\left(0.054 \mathrm{~g} / \mathrm{kg} \mathrm{BW}^{0.75}\right)$, although LaCount et al. [13] used rumen-unprotected L-carnitine. We chose to use this similar dose despite the fact that our product is rumen-protected because our HSed goats presumably need more carnitine as mentioned in the introduction.

The daily total mixed ration was distributed individually to each goat once daily after the morning milking and adjusted at 30\% leftover based on the previous day intake. The ration was formulated to cover requirements according to the Institut National de la Recherche Agronomique (INRA) [14] and consisted of (as fed) alfalfa hay $60.4 \%$, ground barley grain $15 \%$, beet pulp $9.1 \%$, crashed corn grain $7.5 \%$, soybean meal $3 \%$, sunflower meal $3 \%$, molasses $1 \%$, salt $0.6 \%$, sodium bicarbonate $0.2 \%$, and vitamin-mineral corrector for goats $0.2 \%$. The chemical composition and nutritive value of the ration are shown in Table 1. Mineral and vitamin blocks were freely available to each goat $(\mathrm{Na}, 36.74 \%$; $\mathrm{Ca}, 0.32 ; \mathrm{Mg}, 1.09 \%$; Zn, 5 g/kg; Mn, 1.5 g/kg; S, 912 mg/kg; Fe, 304 mg/kg; I, 75 mg/kg; Co, 50 mg/kg; Se, $25 \mathrm{mg} / \mathrm{kg}$; Ovi bloc, Sal Cupido, Barcelona, Spain). Clean water was permanently available at ambient temperature. 
Table 1. Chemical composition and nutritive value of the ration expressed on dry matter (DM) basis.

\begin{tabular}{lc}
\hline Item & Total Mixed Ration \\
\hline Component, $\%$ & \\
Dry matter & 88.2 \\
Organic matter & 88.1 \\
Crude protein & 17.7 \\
Ether extract & 1.79 \\
Neutral detergent fiber & 39.3 \\
Acid detergent fiber & 28.6 \\
Nutritive value & \\
$\mathrm{UEL}^{2} / \mathrm{kg}$ & 1.08 \\
$\mathrm{UFL}^{3} / \mathrm{kg}$ & 0.76 \\
$\mathrm{PDI}^{4} \mathrm{~g} / \mathrm{kg}$ & 94.2 \\
$\mathrm{PDIA}^{5} \mathrm{~g} / \mathrm{kg}$ & 45.5 \\
$\mathrm{RPB}^{6}{ }^{6} \mathrm{~g} / \mathrm{kg}$ & 31.6 \\
$\mathrm{Ca} \mathrm{abs}, \mathrm{g} / \mathrm{kg}$ & 2.73 \\
$\mathrm{P}_{\mathrm{abs}}, \mathrm{g} / \mathrm{kg}$ & 0.84 \\
\hline
\end{tabular}

\footnotetext{
${ }^{1}$ Calculated according to the Institut National de la Recherche Agronomique (INRA, 2018). ${ }^{2}$ Fill units for dairy goats (1 UEL $=1 \mathrm{~kg}$ DM of reference grass). ${ }^{3}$ Net energy for lactation (1 UFL $=1.76 \mathrm{Mcal}$ of NEL). ${ }^{4}$ Protein digestible in the intestine from dietary and microbial origin. ${ }^{5}$ Protein digestible in the intestine from dietary origin. ${ }^{6}$ Rumen protein balance.
}

\subsection{Sample Collection, Analyses, and Measurements}

Rectal temperatures and respiratory rates were daily recorded at 0800, 1200, and $1700 \mathrm{~h}$. Rectal temperature was measured by a digital clinical thermometer (Model ICO Technology "mini color", Barcelona, Spain; range, 32.0 to $43.9^{\circ} \mathrm{C}$; accuracy, $\pm 0.1{ }^{\circ} \mathrm{C}$ ), whereas number of inhalations and exhalations counted during $60 \mathrm{~s}$ indicated the respiratory rate.

Feed intake was recorded daily throughout the experiment. A feed sample was collected before the beginning of the experimental period and was ground through a $1 \mathrm{~mm}$ stainless steel screen, and then analyzed for DM, acid detergent fiber, neutral detergent fiber, and ash according to the official analytical methods [15]. The Dumas method [15] with a Leco analyzer (Leco Corporation, St. Joseph, MI) was used for crude protein determinations.

A sample of 5\% total orts was collected daily during the measurement period and mixed together to make a composite of orts per each goat and period. Particle size of the ration and orts were measured according to Heinrichs and Kononoff [16]. The Penn State Particle Separator (DSE 2013-186, PA) was used. The average particle size was calculated using a spreadsheet downloaded from the Penn State Extention Website (https://extension.psu.edu/penn-state-particle-separator).

Milk yield of individual goats was weighed at each milking throughout the experiment using an electronic scale (Mobba Barcelona). Milk composition was evaluated for $2 \mathrm{~d}$ (d 14 and 15 of each period). A composite milk sample from the morning and afternoon milkings (approximately $100 \mathrm{~mL}$ ) was collected and preserved with an antimicrobial tablet (Bronopol, Broad Spectrum Microtabs II, D\&F Control Systems, San Ramon, CA) at $4{ }^{\circ} \mathrm{C}$ until analysis. Refrigerated milk samples were sent to the Laboratori Interprofessional Lleter de Catalunya (ALLIC, Cabrils, Barcelona, Spain) for the analyses of major components (total solids, fat, protein, and lactose) using medium infrared spectrophotometry (MilkoScan FT2, Foss, DK-3400 Hillerød, Denmark), and somatic cell count using an automatic cell counter (Fossomatic 5000, Foss Electric, Hillerød, Denmark) previously calibrated for goat milk.

Goats were weighed before feeding at the beginning and the end of each experimental period by a scale (model Tru-Test AG500 Digital Indicator, Auckland, New Zealand; accuracy, $\pm 0.5 \mathrm{~kg}$ ). The scale was calibrated by a $5 \mathrm{~kg}$ weight before every weighing. The subcutaneous fat thickness was measured by ultrasonography according to Teixeira et al. [17]. The ultrasound images were taken using a VET 180 Plus ultrasound (Sonosonite, Bothell, WA) with a $5 \mathrm{MHz}$ probe (veterinary model). When the ultrasound images were taken at the breast bone, goats were restrained in dorsal recumbency 
on a table. The fat thickness was measured in a perpendicular position to the ventral midline at the level of the third and fourth sternebrae. Images were then processed using an image analysis program (ImageJ v.1.48, National Institutes of Health; available at imagej.nih.gov/ij/download.html). Three measurements of the distance between the skin and the sternum were done for each goat.

Blood samples were taken at the last day of each period from the jugular vein into $10 \mathrm{~mL}$ vacutainers with K2-EDTA (BD Diagnostics, Franklin Lakes, NJ) before feeding. Plasma was obtained by the centrifugation of blood for $15 \mathrm{~min}$ at $1500 \times \mathrm{g}$ and stored at $-30{ }^{\circ} \mathrm{C}$ until the analysis of NEFA, BHB, triglycerides, and cholesterol. The NEFA were determined by colorimetric enzymatic test ACS-ACOD method using a commercial kit (Wako Chemicals, Neuss, Germany). The BHB was determined by kinetic enzymatic method using commercial kit (Ranbut, Randox, UK). Cholesterol was analyzed by the enzymatic method (cholesterol esterase/peroxidase), whereas triglycerides were analyzed with enzymatic method (glycerol phosphate oxidase) using an Olympus analyzer (Olympus AU400, Dusseldorf, Germany). Blood carnitine fractions (free carnitine, acetyl carnitine, and total carnitine) were determined using a quasi-solid phase extraction without derivatization reactions by means of normal-phase liquid chromatography and electro spray ionization tandem mass spectrometry (Applied Biosystems, Darmstadt, Germany) according to Hirche et al. [18].

At the end of each period, additional blood samples (approximately $0.5 \mathrm{~mL}$ ) were collected by insulin syringes ( $1 \mathrm{~mL}$; BD Micro-Fine, BD Medical-Diabetes Care, Franklin Lakes, NJ), before feeding and immediately analyzed for major ions and metabolites. A single drop of blood was applied to disposable cartridges containing biochemical and silicon chip technology (i-STAT Chem8+, Abbott Point of Care, Princeton, NJ). Then, the cartridge was inserted into an i-STAT handheld analyzer, and glucose, urea, $\mathrm{Cl}, \mathrm{Na}, \mathrm{K}$, ionized $\mathrm{Ca}$, total $\mathrm{CO}_{2}$ concentration, anion gap, hematocrit, hemoglobin, creatinine, and base excess were obtained.

\subsection{Statistical Analyses}

Data were analyzed by the PROC MIXED for repeated measurements of SAS v. 9.1.3 (SAS Institute Inc., Cary, NC). The statistical mixed model contained the fixed effects of the temperature (TN and HS), dietary supplementation (CON and CAR), experimental day, period; the random effect of the animal; the interactions of temperature $\times$ supplementation, temperature $\times$ period, supplementation $\times$ period; and the residual error. The model considered the possible carryover effects of previous HS periods through the temperature $\times$ period interaction. For the data of rectal temperature and respiratory rate measured at 0900, 1200, and 1700, a fixed factor of the hour of day was added to the model. For the data of blood metabolites, and changes of BW and fat thickness, the PROC MIXED was used without repeated measures, and consequently the day effect was removed from the model. Differences between least square means were determined with the PDIFF test of SAS. Significance was declared at $p<0.05$ and tendency at $p<0.10$ unless otherwise indicated.

\section{Results and Discussion}

\subsection{Carnitine Concentrations in Blood}

Blood basal concentrations (samples taken before feeding) of L-carnitine fractions are shown in Table 2. All L-carnitine fractions (i.e., free-, acetyl-, and total-carnitine) in plasma increased $(p<0.01)$ almost three times by CAR supplementation in both TN and HS conditions. LaCount et al. [19] reported that carnitine concentrations in plasma and liver increase when rumen-unprotected L-carnitine is administered into either the rumen or abomasum of dairy cows, indicating that both sites of administration are equally effective for increasing carnitine concentrations in tissues. LaCount et al. [13] also reported a linear increase in plasma and milk carnitine concentrations as dietary carnitine concentration increased. Additionally, Carlson et al. [10] supplemented periparturient dairy cows with $0.046,0.382$, and $0.763 \mathrm{~g} \mathrm{L-carnitine} / \mathrm{kg} \mathrm{BW}^{0.75}$ in the diet and detected that total carnitine concentration in plasma increased four to 10 times by the two higher doses. 
Table 2. Least squares means for L-carnitine fraction concentrations $(\mu \mathrm{mol} / \mathrm{L})$ in plasma of dairy goats under thermo-neutral (TN) or heat stress (HS) conditions. In each ambient temperature, goats were fed a control diet $(\mathrm{CON})$ or supplemented with $1 \mathrm{~g}$ L-carnitine (CAR).

\begin{tabular}{|c|c|c|c|c|c|c|c|c|}
\hline \multirow{2}{*}{ L-Carnitine } & \multicolumn{2}{|c|}{ TN } & \multicolumn{2}{|c|}{ HS } & \multirow{2}{*}{ SEM } & \multicolumn{3}{|c|}{ Effect $^{1}(p=)$} \\
\hline & CON & CAR & CON & CAR & & $T$ & $\mathrm{C}$ & $\mathrm{T} \times \mathrm{C}$ \\
\hline Free & 20.42 & 61.23 & 18.42 & 50.50 & 4.06 & 0.13 & 0.01 & 0.30 \\
\hline Acetyl-carnitine & 6.79 & 17.49 & 6.90 & 21.24 & 2.08 & 0.35 & 0.01 & 0.38 \\
\hline Total & 26.78 & 78.30 & 24.90 & 71.30 & 4.32 & 0.32 & 0.01 & 0.56 \\
\hline
\end{tabular}

In a preliminary work, we measured the in situ degradability of the CAR product, and observed that $72.8 \%$ of CAR dry matter disappeared at $16 \mathrm{~h}$. Despite this high disappearance in the rumen, CAR in the current study was efficiently absorbed, as indicated by the elevated levels of carnitine in plasma (Table 2). This relatively high solubility does not necessarily mean that the L-carnitine was degraded in the rumen. In fact, rumen microorganisms are not able to completely degrade the solubilized L-carnitine, as dietary supplementation with rumen-unprotected carnitine resulted in elevated blood levels of carnitine in dairy cows $[10,12,20]$.

Free L-carnitine represented approximately $75 \%$ of total L-carnitine in the plasma of our goats (Table 2). Free L-carnitine concentrations numerically decreased ( $-14 \%$ on average; $p<0.13$ ) by HS, and it seems that this free carnitine was transformed to acetyl-carnitine (more than $16 \%$ of total carnitine was presented as acetyl-carnitine in the HS group). Similarly, Thomson et al., [21] reported that dairy goats exposed to cold stress experienced decreased blood carnitine levels with lower loss in the milk, which resulted in saving $52 \mu$ moles/d of carnitine that most probably was used for the increment in fatty acid oxidation. Overall, CAR supplemented in the current experiment was absorbed efficiently and was available in blood for metabolism in both TN and HS goats.

\subsection{Rectal Temperature and Respiratory Rate}

The HS goats showed greater $(p<0.001)$ rectal temperatures and respiratory rates than TN goats at 0800,1200 , and $1700 \mathrm{~h}$ (Table 3). Compared to TN goats, HSed goats experienced an increment in rectal temperatures $\left(0.65\right.$ to $1.25^{\circ} \mathrm{C}$ ) and respiratory rates (53 to 91 breaths $/ \mathrm{min}$ ), with the highest values recorded at $1700 \mathrm{~h}$ when the heat load was at its maximal level. This agrees with the results of Sivakumar et al. [22], Hamzaoui et al. [4], and Contreras-Jodar et al. [6], where goats exposed to HS experience high rectal temperatures and respiratory rates. The increment in respiratory rate under HS conditions is a known mechanism for dissipating heat load by pulmonary evaporation. The supplementation with CAR had no effect on rectal temperature or respiratory rate throughout the day.

\subsection{Feed Intake and Feed Sorting}

Average DM intake decreased in HS animals by $26 \%$ throughout the experimental period $(1.90 \pm 0.10 \mathrm{~kg} / \mathrm{d}$ vs. $2.58 \pm 0.10 \mathrm{~kg} / \mathrm{d} ; p<0.001$; Table 4$)$. Goats in the current study were in mid lactation and the reduction of DM intake by heat stress was greater than that previously observed in HS dairy goats during late lactation [4]. On the other hand, CAR supplementation did not affect DM intake, which is in accordance with the results found in cows supplemented with 0.046 or 0.382 $\mathrm{g}$ L-carnitine $/ \mathrm{kg} \mathrm{BW}^{0.75}$ [10]. However, when cows were fed a high dose of L-carnitine $(0.763 \mathrm{~g} / \mathrm{kg}$ $\left.\mathrm{BW}^{0.75}\right)$, DM intake decreased, plausibly because of increased hepatic ATP production [10].

Heat-stressed goats tended $(p<0.06)$ to eat longer particle size compared to TN goats, as the average particle length of their orts decreased by $27 \%(6.2 \pm 0.64 \mathrm{~mm}$ vs. $4.5 \pm 0.64 \mathrm{~mm}$ for TN and HS, respectively; Table 4). Feed sorting against short particles (that contain greater energy content than longer particles) in addition to the fact that feed intake is reduced by HS would exacerbate challenges associated with reduced energy intake. Castro-Costa et al. [23] reported that HS decreases rumen $\mathrm{pH}$ in dairy goats eating the same amount of food as TN goats. Although we did not measure rumen $\mathrm{pH}$ 
in the current study, we speculate that our HS goats ate longer particles to manage possible low $\mathrm{pH}$ in the rumen. Additional work is needed to explore the relationship between rumen $\mathrm{pH}$ and feed sorting behavior under HS conditions. The increased feed sorting for long particles (presumably forage particles) is in contrast to the common nutritional practice of reducing ration forage content during HS [2]. No effect of CAR supplementation on the orts particle size was observed.

Table 3. Least squares means for respiratory rate and body temperature of dairy goats under thermo-neutral (TN) and heat stress (HS) conditions. In each ambient temperature, goats were fed a control diet (CON) or supplemented with $1 \mathrm{~g}$ L-carnitine (CAR).

\begin{tabular}{|c|c|c|c|c|c|c|c|c|}
\hline \multirow{2}{*}{ Item } & \multicolumn{2}{|c|}{ TN } & \multicolumn{2}{|c|}{ HS } & \multirow{2}{*}{ SEM } & \multicolumn{3}{|c|}{ Effect $^{1}(p=)$} \\
\hline & $\mathrm{CON}$ & CAR & CON & CAR & & $\mathbf{T}$ & $\mathrm{C}$ & $\mathrm{T} \times \mathrm{C}$ \\
\hline \multicolumn{9}{|c|}{ Rectal temperature, ${ }^{\circ} \mathrm{C}$} \\
\hline $0800 \mathrm{~h}$ & 38.5 & 38.5 & $39.1^{\mathrm{c}}$ & $39.2^{c}$ & 0.05 & 0.001 & 0.290 & 0.146 \\
\hline $1200 \mathrm{~h}$ & 38.6 & 38.5 & $39.7^{b}$ & $39.7^{\mathrm{b}}$ & 0.05 & 0.001 & 0.520 & 0.863 \\
\hline $1700 \mathrm{~h}$ & 38.7 & 38.6 & $39.9^{\mathrm{a}}$ & $39.9^{\mathrm{a}}$ & 0.05 & 0.001 & 0.222 & 0.648 \\
\hline Average & 38.6 & 38.5 & 39.6 & 39.6 & 0.04 & 0.001 & 0.762 & 0.464 \\
\hline \multicolumn{9}{|c|}{ Respiratory rate, breaths/min } \\
\hline $0800 \mathrm{~h}$ & 36 & 35 & $88^{\mathrm{b}}$ & $88^{\mathrm{b}}$ & 3.0 & 0.001 & 0.939 & 0.933 \\
\hline $1200 \mathrm{~h}$ & 36 & 36 & $126^{\mathrm{a}}$ & $121^{\mathrm{a}}$ & 3.0 & 0.001 & 0.455 & 0.282 \\
\hline $1700 \mathrm{~h}$ & 40 & 39 & $133^{\mathrm{a}}$ & $127^{a}$ & 3.0 & 0.001 & 0.247 & 0.144 \\
\hline Average & 37 & 37 & 116 & 112 & 2.4 & 0.001 & 0.430 & 0.542 \\
\hline
\end{tabular}

${ }^{1}$ Effects of temperature (T), CAR supplementation (C), and their interaction $(\mathrm{T} \times \mathrm{C}) .{ }^{\text {a-c }}$ Values within the same column (at 0800, 1200, and $1700 \mathrm{~h}$ ) for each parameter with different superscripts differ $(p<0.05)$.

\subsection{Milk Yield and Composition}

As shown in Table 4 , milk yield tended $(p<0.06)$ to decrease by $11 \%$ in goats exposed to HS $(1.63 \pm 0.09 \mathrm{~kg} / \mathrm{d})$ compared to TN goats $(1.84 \pm 0.09 \mathrm{~kg} / \mathrm{d})$. This reduction was similar to what observed by Hamzaoui et al. [24] in HSed dairy goats at mid lactation. The consequences of high ambient temperature in lactating dairy ruminants are well known [1,2,5], which include increased body temperature, reduced DM intake, and consequently, altered milk yield and composition. Milk composition was also affected by high ambient temperature (Table 4); the HS goats producing milk with lower fat $(p<0.08)$, protein $(p<0.05)$, and lactose $(p<0.01)$ contents than TN goats.

Table 4. Least squares means for feed intake, average particle size of the orts, and milk production of dairy goats under thermo-neutral (TN) or heat stress (HS) conditions. In each ambient temperature, goats were fed a control diet (CON) or supplemented with $1 \mathrm{~g}$ L-carnitine (CAR).

\begin{tabular}{|c|c|c|c|c|c|c|c|c|}
\hline \multirow{2}{*}{ Item } & \multicolumn{2}{|c|}{ TN } & \multicolumn{2}{|c|}{ HS } & \multirow{2}{*}{ SEM } & \multicolumn{3}{|c|}{ Effect $^{1}(p=)$} \\
\hline & CON & CAR & CON & CAR & & $\mathrm{T}$ & $\mathrm{C}$ & $T \times C$ \\
\hline DM intake, $\mathrm{kg} / \mathrm{d}$ & 2.60 & 2.56 & 1.85 & 1.95 & 0.16 & 0.007 & 0.976 & 0.859 \\
\hline Orts average particle size, $\mathrm{mm}$ & 5.31 & 7.92 & 3.99 & 5.02 & 1.10 & 0.057 & 0.238 & 0.674 \\
\hline Milk yield, $\mathrm{kg} / \mathrm{d}$ & 1.90 & 1.80 & 1.59 & 1.69 & 0.14 & 0.059 & 0.955 & 0.730 \\
\hline $\mathrm{FCM}, \mathrm{L} / \mathrm{d}^{2}$ & 2.28 & 2.15 & 1.81 & 1.90 & 0.19 & 0.028 & 0.880 & 0.765 \\
\hline \multicolumn{9}{|l|}{ Milk composition, \% } \\
\hline Total solids & 8.89 & 8.91 & 8.37 & 8.46 & 0.19 & 0.005 & 0.926 & 0.961 \\
\hline Fat & 4.33 & 4.21 & 4.02 & 3.96 & 0.20 & 0.076 & 0.729 & 0.984 \\
\hline Protein & 3.51 & 3.54 & 3.14 & 3.22 & 0.18 & 0.049 & 0.951 & 0.989 \\
\hline Lactose & 4.64 & 4.65 & 4.47 & 4.47 & 0.06 & 0.006 & 0.991 & 0.788 \\
\hline Fat yield, $\mathrm{g} / \mathrm{d}$ & 85.8 & 80.7 & 66.5 & 69.3 & 7.8 & 0.015 & 0.864 & 0.844 \\
\hline Protein yield, $\mathrm{g} / \mathrm{d}$ & 69.1 & 64.6 & 50.3 & 54.5 & 6.0 & 0.008 & 0.991 & 0.737 \\
\hline Somatic cell count, Log & 5.97 & 6.00 & 6.30 & 6.22 & 0.23 & 0.276 & 0.873 & 0.842 \\
\hline
\end{tabular}

${ }^{1}$ Effects of temperature (T), CAR supplementation (C), and their interaction $(\mathrm{T} \times \mathrm{C}) .{ }^{2}$ Fat corrected milk at $3.5 \%$; $\mathrm{FCM}=\mathrm{kg}$ of milk yield $\times[0.432+0.162 \times($ fat $\%)]$.

We hypothesized that carnitine synthesis is reduced by the potential inflammation induced by HS, and that CAR supplementation would cover the shortage in the production of endogenous carnitine. 
Additionally, if the HSed goats mobilize body fat due to the reduced feed intake, supplemented CAR would improve the oxidation of mobilized fatty acids. This could improve the efficiency of energy use and reduce the adverse effect of HS on milk production. However, CAR supplementation did not affect milk yield or milk composition (Table 4), indicating that CAR supplementation has no beneficial effects on milk production of HSed goats. Similarly, LaCount et al. [19] found no effect of CAR supplementation on milk production of non-heat-stressed dairy cows. Nevertheless, feed-restricted dairy cows (with high blood NEFA levels) produced greater 3.5\% fat-corrected milk when supplemented with abomasum infused L-carnitine [25]. Furthermore, dairy cows supplemented with rumen-protected L-carnitine, from one week before calving to four weeks after parturition, produced similar milk yield to un-supplemented cows, but their milk contained greater fat and protein [26]. These studies indicate that carnitine supplementation may be required during the situations of DM intake depression that cause body fat mobilization and elevated blood NEFA (e.g., transition period or feed restriction). Although HS in the current study reduced feed intake by $26 \%$, HS and TN goats had similar blood NEFA levels (see the blood metabolites section), which may explain why CAR did not improve the performance of HSed goats.

\subsection{Body Weight and Subcutaneous Fat Assessment}

Changes in BW and subcutaneous (s.c.) fat were expressed as the difference between the values at the start and the end of each experimental period (Figure 1). On average, HSed goats lost $146 \mathrm{~g} / \mathrm{d}$ of BW, whereas TN goats gained $139 \mathrm{~g} / \mathrm{d}$, agreeing with the results of Hamzaoui et al. [4]. A portion of the BW changes of TN and HS goats included the inevitable variations in the digestive tract content (reduced feed intake in HS), which were unknown in our data. Supplementation with L-carnitine did not affect the overall BW variation. This agrees with the results found in growing sheep in which L-carnitine do not affect average daily gain [27].

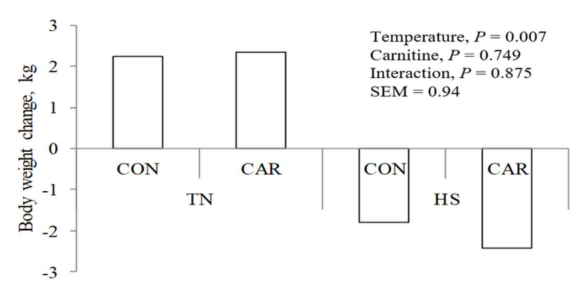

(A)

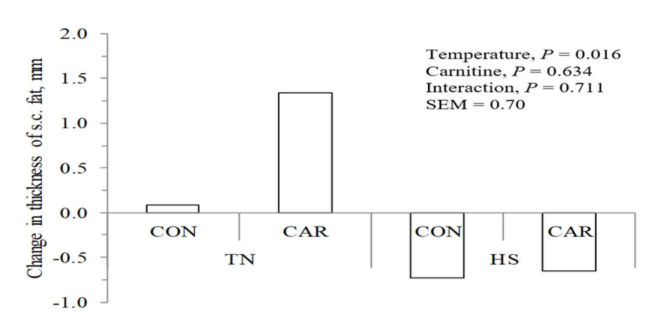

(B)

Figure 1. Changes in body weight (A) and subcutaneous fat thickness (B), measured as the difference between values at the start and the end of each experimental period in dairy goats under thermo-neutral (TN) or heat stress (HS) conditions. In each ambient temperature, goats were fed a control diet (CON) or supplemented with $5 \mathrm{~g}$ CAR containing $1 \mathrm{~g}$ pure L-carnitine.

The values of ultrasound fat measurements (Figure 1) revealed that HSed goats had lower s.c. fat thickness compared to TN $(-0.72$ vs. $+0.64 \mathrm{~mm} ; p<0.05)$. L-carnitine supplementation did not affect s.c. fat mobilization in accordance with the results of Hajilou et al. [28], who detected no changes in s.c. fat in finishing bulls supplemented with L-carnitine. In addition, BW variation and ultrasound measurements were positively correlated $(r=0.54)$, indicating that HSed goats in negative energy balance would mobilize body fat. Mendizabal et al. [29] indicated that, for the processes of storage and mobilization of fat reserves in adult goats, the s.c. fat was particularly active and appears to be highly specialized for lipid accumulation and mobilization. 


\subsection{Blood Metabolites}

Blood metabolites of TN and HSed goats with and without L-carnitine supplementation are shown in Table 5. L-carnitine supplementation did not affect $(p>0.10)$ blood urea or glucose levels. Previous reports revealed that carnitine supplementation increases insulin secretion and hepatic glucose output by incrementing the flux of metabolites through pyruvate carboxylase [10,30]. In agreement with this notion, Greenwood et al. [20] observed that blood glucose levels increase by $3 \%$ in growing steers supplemented with carnitine. Nevertheless, blood glucose in our goats was not affected by CAR supplementation.

Table 5. Least squares means for blood metabolites in dairy goats under thermo-neutral (TN) or heat stress (HS) conditions. In each ambient temperature, goats were fed a control diet (CON) or supplemented with $1 \mathrm{~g}$ L-carnitine (CAR).

\begin{tabular}{|c|c|c|c|c|c|c|c|c|}
\hline \multirow{2}{*}{ Item } & \multicolumn{2}{|c|}{ TN } & \multicolumn{2}{|c|}{ HS } & \multirow{2}{*}{ SEM } & \multicolumn{3}{|c|}{ Effect $^{1}(p=)$} \\
\hline & $\mathrm{CON}$ & CAR & CON & CAR & & $T$ & C & $T \times C$ \\
\hline $\mathrm{Na}, \mathrm{mmol} / \mathrm{L}$ & 148.0 & 147.6 & 147.0 & 147.0 & 0.52 & 0.349 & 0.881 & 0.299 \\
\hline $\mathrm{K}, \mathrm{mmol} / \mathrm{L}$ & 3.47 & 3.47 & 3.84 & 3.87 & 0.15 & 0.042 & 0.754 & 0.243 \\
\hline Ionized $\mathrm{Ca}, \mathrm{mmol} / \mathrm{L}$ & 1.28 & 1.27 & 1.27 & 1.31 & 0.02 & 0.066 & 0.378 & 0.310 \\
\hline $\mathrm{Cl}, \mathrm{mmol} / \mathrm{L}$ & 103.8 & 103.6 & 107.9 & 107.8 & 0.67 & 0.007 & 0.109 & 0.497 \\
\hline $\mathrm{TCO}_{2}, \mathrm{mmol} / \mathrm{L}$ & 25.7 & 25.9 & 20.9 & 21.2 & 0.69 & 0.009 & 0.678 & 0.871 \\
\hline Anion gap & 23.0 & 22.7 & 22.8 & 23.1 & 0.54 & 0.707 & 0.247 & 0.869 \\
\hline Hematocrit, \% PCV & 17.6 & 18.6 & 17.7 & 18.4 & 0.92 & 0.770 & 0.609 & 0.899 \\
\hline Hemoglobin, g/dL & 5.98 & 6.31 & 6.05 & 6.26 & 0.31 & 0.778 & 0.599 & 0.891 \\
\hline Glucose, $\mathrm{mg} / \mathrm{dL}$ & 59.1 & 59.6 & 59.9 & 58.6 & 1.71 & 0.743 & 0.962 & 0.733 \\
\hline Urea, mg/dL & 23.2 & 24.5 & 18.3 & 19.8 & 1.85 & 0.008 & 0.710 & 0.971 \\
\hline Creatinine, $\mathrm{mg} / \mathrm{dL}$ & 0.47 & 0.52 & 0.57 & 0.54 & 0.02 & 0.007 & 0.906 & 0.211 \\
\hline Triglycerides, mg/dL & 17.6 & 18.0 & 17.1 & 17.1 & 1.3 & 0.878 & 0.660 & 0.501 \\
\hline Cholesterol, mg/dL & 74.7 & 76.2 & 85.5 & 79.9 & 5.8 & 0.219 & 0.911 & 0.733 \\
\hline non-esterified fatty acids, $\mathrm{mmol} / \mathrm{L}$ & 0.08 & 0.13 & 0.15 & 0.12 & 0.02 & 0.291 & 0.333 & 0.276 \\
\hline B-hydroxybutyrate, $\mathrm{mmol} / \mathrm{L}$ & 0.72 & 0.70 & 0.80 & 0.85 & 0.11 & 0.187 & 0.972 & 0.932 \\
\hline
\end{tabular}

${ }^{1}$ Effects of temperature $(\mathrm{T})$, CAR supplementation $(\mathrm{C})$, and their interaction $(\mathrm{T} \times \mathrm{C})$.

Supplementation with L-carnitine did not affect blood NEFA, BHB, cholesterol, or triglycerides concentrations (Table 5). Dairy cows in early lactation have decreased blood NEFA and cholesterol concentrations when supplemented with $10 \mathrm{~g} / \mathrm{d}$ of protected carnitine [31]. In addition, Citil et al. [32] reported that feed supplementation with L-carnitine decreases serum triglycerides and cholesterol in lactating ewes. Nevertheless, and agreeing with our findings, Carlson et al. [25] reported that plasma NEFA is not altered in mid-lactation dairy cows infused with L-carnitine.

The decrease $(p<0.01)$ in blood urea concentration by HS could be explained by their lower DM intake and, consequently, reduced N intake. Despite the reduced feed intake (Table 4), HSed goats were able to keep similar glucose levels to TN goats. Creatinine levels increased $(p<0.01)$ with HS, which might indicate increased muscle degradation. It is possible that some glucogenic AA produced from muscle degradation were used for gluconeogenesis, resulting in keeping similar blood glucose levels. Additionally, Salama et al. [3] reported that HSed goats secrete lower insulin when glucose is infused compared to TN goats, which might be an adaptation to HS and could explain unaltered glucose levels in HS goats.

Values of total blood $\mathrm{CO}_{2}$ were lower in HS compared to TN goats, which agrees with previous studies $[4,22]$. The greater respiratory rate observed in HSed goats (Table 3 ) contributed to washing off of $\mathrm{CO}_{2}$, and consequently a lower concentration of $\mathrm{CO}_{2}$ in blood. The $\mathrm{Cl}^{-}$and $\mathrm{K}^{+}$blood concentrations were greater $(p<0.05)$ in HS than in TN goats. The blood ionized Ca concentration also tended $(p<0.10)$ to be greater in HS $(1.29 \mathrm{mmol} / \mathrm{L})$ compared to TN goats $(1.26 \mathrm{mmol} / \mathrm{L})$. Similarly, Srikandakumar and Johnson [33] reported greater concentrations of $\mathrm{K}, \mathrm{Cl}$, and $\mathrm{Ca}$ in blood of heat-stressed cows. Collier et al. [34] reported that $\mathrm{K}$ requirements in HSed dairy cows increase by as much as $12 \%$ because sweat is high in $\mathrm{K}$. In the current study, blood $\mathrm{K}$ in HSed goats increased by $11 \%$ to meet $\mathrm{K}$ requirements 
despite the reduced mineral intake. However, our goats had free access to mineral-vitamin blocks, which might have allowed them to obtain minerals as needed.

As indicated above, s.c. fat thickness measured by ultrasonography was decreased by HS (Figure 1), indicating that goats would have mobilized body fat reserves. However, both blood NEFA and BHB did not change by HS in the current study (Table 5) and previous studies done in dairy goats [3] and dairy cows [1]. It is possible that there was some degree of body fat mobilization, but NEFA were rapidly taken up by the mammary gland for fat synthesis (milk fat was less affected by HS than milk protein as shown in Table 4) and were not transformed to ketone bodies by the liver. We detected no correlation between blood NEFA and BHB in TN $(\mathrm{r}=0.02 ; p=0.953)$ or HS $(\mathrm{r}=0.18$; $p=0.478$ ) goats.

Finally, and from the viewpoint of animal welfare, the level of HS used in the current study was moderate according to the established levels of HS in dairy goats [12]. Furthermore, we used the minimum possible number of goats $(n=4$; Latin square four $\times$ four) and the shortest time for each period (16 days) to test the effects of L-carnitine. As stated previously, our hypothesis was solid and we expected positive effects of L-carnitine on HS goats, but we were not able to detect such effects. This will avoid unnecessary exposure of animals to HS in the future to test the effects of L-carnitine.

\section{Conclusions}

Heat stress negatively affected the lactational performance of dairy goats. Additionally, heat stress altered feeding behavior as heat-stressed goats tended to consume longer feed particles as an attempt to keep stable rumen $\mathrm{pH}$. Supplementation of thermo-neutral and heat-stressed lactating dairy goats with rumen protected L-carnitine dramatically increased blood carnitine fractions (free-, acetyl-, and total-carnitine). Despite the effective absorption of carnitine, no productive benefits or physiological changes were observed in dairy goats under thermo-neutral or heat stress conditions. Evidence was not obtained to support the hypothesis that carnitine supplementation is needed under heat stress conditions.

Author Contributions: Conceptualization, G.C. and A.A.K.S.; methodology, N.M., X.S., E.A., and A.A.K.S.; data curation, N.M., X.S., and A.A.K.S.; writing-original draft preparation, N.M.; writing-review and editing, A.A.K.S., G.C., and E.A.; funding acquisition, A.A.K.S., and G.C.

Acknowledgments: This work is part of a research project funded by the Spanish Ministry of Economy and Finance (Program I + D + I oriented to Society challenges; Project AGL2013-44061-R) and was also supported by a research scholarship to Mehaba Nabil from the International Centre for Advanced Mediterranean Agronomic Studies (IAMZ, Zaragoza, Spain). The authors are also grateful to the team of SGCE (Servei de Granges i Camps Experimentals) of the UAB for the care of the animals.

Conflicts of Interest: The authors declare no conflict of interest.

\section{References}

1. Baumgard, L.H.; Rhoads, R.P. Effects of heat stress on postabsorptive metabolism and energetics. Annu. Rev. Anim. Biosci. 2013, 1, 311-337. [CrossRef] [PubMed]

2. Salama, A.A.K.; Caja, G.; Hamzaoui, S.; Such, X.; Albanell, E.; Badaoui, B.; Loor, J.J. Thermal stress in ruminants: Responses and strategies for alleviation. In Animal Welfare in Extensive Production Systems, 1st ed.; Villalba, J.J., Manteca, X., Eds.; 5M Publishing: Sheffield, UK, 2016; pp. 11-36.

3. Salama, A.A.K.; Caja, G.; Hamzaoui, S.; Badaoui, B.; Castro-Costa, A.; Façanha, D.E.; Guilhermino, M.M.; Bozzi, R. Different levels of response to heat stress in dairy goats. Small Rumin. Res. 2014, 121, 73-79. [CrossRef]

4. Hamzaoui, S.; Salama, A.A.K.; Albanell, E.; Such, X.; Caja, G. Physiological responses and lactational performances of late-lactation dairy goats under heat stress conditions. J. Dairy Sci. 2013, 96, 6355-6365. [CrossRef] [PubMed]

5. West, J.W. Effects of heat-stress on production in dairy cattle. J. Dairy Sci. 2003, 86, 2131-2144. [CrossRef] 
6. Contreras-Jodar, A.; Salama, A.A.K.; Hamzaoui, S.; Vailati-Riboni, M.; Caja, G.; Loor, J.J. Effects of chronic heat stress on lactational performance and the transcriptomic profile of blood cells in lactating dairy goats. $J$. Dairy Res. 2018, 85, 423-430. [CrossRef] [PubMed]

7. Palomer, X.; Salvado, L.; Barroso, E.; Vazques-Carrera, M. An overview of the crosstalk and metabolic dysregulation during diabetic cardiomyopathy. Int. J. Cardiol. 2013, 168, 3160-3172. [CrossRef] [PubMed]

8. Vaz, F.; Wanders, R. Carnitine biosynthesis in mammals. Biochem. J. 2002, 429, 417-429. [CrossRef]

9. Randle, P.J. Regulatory interactions between lipids and carbohydrates: The glucose fatty acid cycle after 35 years. Diabetes Metab. Rev. 1998, 14, 263-283. [CrossRef]

10. Carlson, D.B.; McFadden, J.W.; D'Angelo, A.; Woodworth, J.C.; Drackley, J.K. Dietary L-carnitine affects periparturient nutrient metabolism and lactation in multiparous cows. J. Dairy Sci. 2007, 90, 3422-3441. [CrossRef]

11. National Research Council (NRC). A Guide to Environmental Research on Animals; National Academy of Sciences: Washington, DC, USA, 1971.

12. Silanikove, N.; Koluman, N.D. Impact of climate change on the dairy industry intemperate zones: Predications on the overall negative impact and on the positive role of dairy goats in adaptation to earth warming. Small Ruminant Res. 2015, 123, 27-34. [CrossRef]

13. LaCount, D.W.; Ruppert, L.D.; Drackley, J.K. Ruminal degradation and dose response of dairy cows to dietary L-carnitine. J. Dairy Sci. 1996, 79, 260-269. [CrossRef]

14. Institut National de la Recherche Agronomique (INRA). INRA Feeding System for Ruminants; Wageningen Academic Publishers: Wageningen, The Netherlands, 2018.

15. AOAC International. Official Methods of Analysis of AOAC International, 17th ed.; AOAC International: Gaithersburg, MD, USA, 2003; Volume I.

16. Heinrichs, J.; Kononoff, P. Evaluating Particle Size of Forages and TMRs Using the New Penn State Forage Particle Separator; Cooperative Extension DAS; College of Agriculture Science, Pennsylvania State University: University Park, TX, USA, 2002; pp. 2-42.

17. Teixeira, A.; Joy, M.; Delfa, R. In vivo estimation of goat carcass composition and body fat partition by real-time ultrasonography. J. Anim. Sci. 2008, 86, 2369-2376. [CrossRef]

18. Hirche, F.; Fischer, M.; Keller, J.; Eder, K. Determination of carnitine, its short chain acyl esters and metabolic precursors trimethyllysine and $\gamma$-butyrobetaine by quasi-solid phase extraction and MS/MS detection. $J$. Chromatogr. B 2009, 877, 2158-2162. [CrossRef] [PubMed]

19. LaCount, D.W.; Drackley, J.K.; Weigel, D.J. Responses of dairy cows during early lactation to ruminal or abomasal administration of L-carnitine. J. Dairy Sci. 1995, 78, 1824-1836. [CrossRef]

20. Greenwood, R.H.; Titgemeyer, E.C.; Stokka, G.L.; Drouillard, J.S.; Loest, C.A. Effects of L-carnitine on nitrogen retention and blood metabolites of growing steers and performance of finishing steers. J. Anim. Sci. 2001, 79, 254-260. [CrossRef]

21. Thomson, E.M.; Snoswell, A.M.; Clarke, P.L.; Thompson, G.E. Effect of cold exposure on mammary gland uptake of fat precursors and secretion of milk fat and carnitine in the goat. Q. J. Exp. Physiol. 1979, 64, 7-15. [CrossRef] [PubMed]

22. Sivakumar, A.V.N.; Singh, G.; Varshney, V.P. Antioxidants supplementation on acid base balance during heat stress in goats. Asian-australas. J. Anim. Sci. 2010, 23, 1462-1468. [CrossRef]

23. Castro-Costa, A.; Salama, A.A.K.; Moll, X.; Aguiló, J.; Caja, G. Using wireless rumen sensors for evaluating the effects of diet and ambient temperature in non-lactating dairy goats. J. Dairy Sci. 2015, 98, 4646-4658. [CrossRef]

24. Hamzaoui, S.; Salama, A.A.K.; Caja, G.; Albanell, E.; Such, X. Effects of supplementation with propylene glycol in heat-stressed dairy goats. J. Dairy Sci. 2014, 97 (Suppl. 1), 736-737.

25. Carlson, D.B.; Litherland, N.B.; Dann, H.M.; Woodworth, J.C.; Drackley, J.K. Metabolic effects of abomasal L-carnitine infusion and feed restriction in lactating Holstein cows. J. Dairy Sci. 2006, 89, 4819-4834. [CrossRef]

26. Pirestani, A.; Aghakhani, M. The effects of rumen-protected choline and L-carnitine supplementation in the transition period on reproduction, production, and some metabolic diseases of dairy cattle. J. Applied Anim. Res. 2018, 46, 435-440. [CrossRef] 
27. Chapa, A.M.; Fernandez, J.M.; White, T.W.; Bunting, L.D.; Gentry, L.R.; Lovejoy, J.C.; Owen, K.Q. Influence of dietary carnitine in growing sheep fed diets containing non-protein nitrogen. Small Rumin. Res. 2001, 40, 13-28. [CrossRef]

28. Hajilou, M.; Dehghan-Banadaky, M.; Zali, A.; Rezayazdi, K. The effects of dietary L-carnitine and rumen protected choline on growth performance, carcass characteristics and blood and rumen metabolites of Holstein young bulls. J. Appl. Anim. Res. 2014, 42, 89-96. [CrossRef]

29. Mendizabal, J.A.; Delfa, R.; Arana, A.; Eguinoa, P.; Purroy, A. Lipogenic activity in goats (Blancaceltibérica) with different body condition scores. Small Rumin. Res. 2007, 67, 285-290. [CrossRef]

30. Owen, K.Q.; Ji, H.; Maxwell, C.V.; Nelssen, J.L.; Goodband, R.D.; Tokach, M.D.; Tremblay, G.C.; Koo, S.I. Dietary L-carnitine suppresses mitochondrial branched-chain keto acid dehydrogenase activity and enhances protein accretion and carcass characteristics of swine. J. Anim. Sci. 2001, 79, 3104-3112. [CrossRef] [PubMed]

31. Scholz, H.; Kecman, J.; Von Heimendahl, E.; Menn, F.; Ahrens, A. Application of protected L-carnitine in dairy cows during transition and high lactation period. Global J. Sci. Frontier Res. 2014, 14, 41-46.

32. Citil, M.; Karapehlivan, M.; Erdogan, H.M.; Yucayurt, R.; Atakisi, E.; Atakisi, O. Effect of orally administered L-carnitine on selected biochemical indicators of lactating Tuj-ewes. Small Rumin. Res. 2009, 81, 174-177. [CrossRef]

33. Srikandakumar, A.; Johnson, E.H. Effect of heat stress on milk production, rectal temperature, respiratory rate and blood chemistry in Holstein, Jersey and Australian milking Zebu cows. Trop. Anim. Health Prod. 2004, 36, 685-692. [CrossRef]

34. Collier, R.J.; Dahl, G.E.; VanBaale, M.J. Major advances associated with environmental effects on dairy cattle. J. Dairy Sci. 2006, 89, 1244-1253. [CrossRef]

(C) 2019 by the authors. Licensee MDPI, Basel, Switzerland. This article is an open access article distributed under the terms and conditions of the Creative Commons Attribution (CC BY) license (http://creativecommons.org/licenses/by/4.0/). 